\title{
Corporate Higher Education: Models And Examples
}

Joan H. Coll, (Email: colljoan@shu.edu), Seton Hall University Brownyn DeWitt, Seton Hall University

\begin{abstract}
Corporate education has become a major influence in higher education today. The goal of this initiative is to explore the forms that higher corporate education takes. Among the most prevalent are: specifically designed university programs, partnership programs between a company and a university, and corporation designed programs created and offered to meet the specific needs of educating their employees in training matters and providing development within the corporate structure. While there is no set formula for fashioning a successful program the myriad variations provide an opportunity to explore the pros and cons of each model. An example of a successful corporate higher education program is explored.
\end{abstract}

W

hat is corporate education? Corporate education has several definitions. Corporate education can be university programs that are specifically designed to enhance or develop the corporate manager. Corporate education is also defined to describe a partnership between a university (credits are awarded) and a company. The last popular definition is one that focuses on education provided by the corporation.

\section{Training vs. Development}

Corporations, in general, do not distinguish between training and development. Both concepts are subsumed under the umbrella of corporate education. However, there are distinct differences that must be addressed.

Training

The purpose and scope of training is narrow and well-defined, and is typically short-term with outcomes that can be specified in detail as competencies or skills (Bryans and Smith, 2001). Work-based training naturally focuses on the skills individuals need in their current employment. "Other forms of training may focus on the skills needed to secure employment, such as communication skills or the skills of information technology. (Bryans and Smith.) Training is typically something that is simple to learn." It is something that is for the employee's current job. Perhaps training is best described as what it is not. Training is not forward looking. Training is not growth oriented for the individual. Training is not intended to be a career-advancing tool. However, it is an important function in corporate education.

\section{Education}

On the other hand, when we think of development we consider wider personal growth and long term change for the employee. Development according to Bryans and Smith is longer-term and more open ended: "it is unlikely to be focused on one's present employment and may well be connected only in the loosest way with the needs of the employing organization as a whole. Such companies as Ford Motor Company give their employees

Readers with comments or questions are encouraged to contact the authors via email. 
"learning credits" to learn a foreign language or whatever they want to learn. These efforts show Ford Motor Company's commitment to this form of education - development." (Bryans and Smith.) Training is individualistic and does not specifically attempt to enhance organizational, social or political factors. It does focus on improving job-related skills. Development, on the other hand, looks to create a permanent change in the individual's behavior. It is transferable from one situation to the other and is not directly related to a specific job task. Development is forward thinking. Development is growth oriented. Development is a career-advancing tool. Development is typically thought to be for upper management or for employees interested in advancing or who are selected to join higher levels of management.

Having acknowledged that there is a difference between training and development it should be noted that this is not the case in most corporate education programs. Most corporate educational programs intertwine the two bringing us back to our original question, "What is corporate education"? The answer depends on the corporation being discussed and their interpretation of corporate education.

\section{The Three Types Of Corporate Education}

Initially we mentioned the three types of corporate education: 1) the university management program, 2) the corporate partnership program and, 3) the corporation itself doing the educating. We will explore each option.

\section{University Management Programs}

University management programs are programs developed by universities that are offered to advance the executives' careers through an advanced business degree. They center their efforts on accommodating the executives' needs. The programs are relatively short in duration dispensing large amounts of information in a short amount of time. Programs are offered both on campus and at sites convenient to the participating corporations. These types of programs are geared toward the executive who seeks additional development. (Harvard Business School Brochure, Executive Education, www.exed.hbs.edu/about/why.html.)

University management programs are offered by a variety of institutions of higher learning and include such prestigious schools as Harvard Business School, Duke, and MIT. Harvard Business School (HBS) offers oncampus learning programs for executives. These schools boast that "successful business leaders understand that learning is leverage, and HBS, offers an interactive, actionable learning experience for a lifetime of leadership. "Senior executives seeking to reinvigorate their outlooks will discover that HBS provides a pivotal opportunity to step back from day-to-day business, explore new ideas, and experience the freedom to learn." (Harvard Business School Brochure, Executive Education, www.exed.hbs.edu/about/why.html.) HBS offers the business executive unparalleled opportunities to:

- $\quad$ View business through the lens of general management,

- Sort out real world problems with faculty who have vast experience in real business situations,

- $\quad$ Experience the HBS renowned case-study method at its source,

- Interaction with a select group of peers,

- $\quad$ "Retool thinking, management, and analytical skills in a dynamic environment." (Harvard Business School Brochure, Executive Education, www.exed.hbs.edu/about/why.html.)

Additionally, HBS will customize a program to meet the goals of the corporation. "More specifically HBS states the following: "HBS develops standard-setting, customized learning experiences that create competitive advantage for leading global corporations." (Harvard Business School Brochure, Executive Education, www.exed.hbs.edu/about/why.html.) These programs are: 1) tailored to each company's complex business needs, leadership challenges and organizational realities; 2) focused on advancing a company's strategic direction and implementation capabilities; and 3) designed to help communicate the knowledge and insight gained by participants for application throughout their organizations." (Harvard Business School Brochure, Executive Education, www.exed.hbs.edu/about/why.html.) The goal of the customized corporate educational experienced offered by HBS is to make the learning appropriate and actionable for the corporation for its objectives. 
A second university education program examined is that of Duke University. Duke University uses the model, the Personal Learning Systems ("PLS"). This system builds on executives' existing strengths and prepares them for future challenges. (Personal Learning System, Duke University, http://www.dukece.com/products/ index/htm.)

Duke claims that their PLS is "One-to-One Executive Development designed to accelerate leadership capability. It focuses on the individual executive, whereas traditional executive education is aimed at developing organizational or group skills, competencies, or capabilities." (Personal Learning System, Duke University, http://www.dukece.com/products/index/htm)

PLS further boasts that it offers "an individualized learning plan based on an assessment of the individual and his/her immediate corporate environment in the context of the industry." (Personal Learning System, Duke University, http://www.dukece.com/products/index/htm.) A student is then assigned a world-class executive coach who coordinates all aspects of the learning plan. To implement the plan, PLS draws on an extensive database of learning resources and a network of leading executive coaches and educators. The corporate expectation is "to leverage the performance of the most senior executives in three domains: behavioral, strategic thinking and action, and business content knowledge." (Personal Learning System, Duke University, http://www.dukece.com/ products/index/htm.)

Executive programs of corporate education are situated away from the corporate structure itself and are developmentally focused. Skill based corporate education tends to be in-house.

\section{Corporate Partnership Programs}

As demonstrated by the above, each program is as different as the university in which it is housed. The executive is exposed to developmental skills, not training skills. In this model of corporate education we see the emphasis shift from educating upper level management to educating middle level management. The programs are credit-earning (credits are awarded by a university) but are sponsored by the corporations. Typically they are located at the corporation. Such credit earning corporate educational programs are sometimes facilitated by professional educational consulting firms that come to the corporation to help set up educational programs the employees. One example is the consulting firm, DPT Consulting Group, Inc. (http://www.dptconsulting.com/consulting_cu.htm.)

This group's function is to create a "Corporate University." DPT states that the definition of a corporate university is that "it provides a metaphor and a strategic function for knowledge management, performance improvement, and people development within organizations. In essence, the corporate university is a learning laboratory, serving as the driving force for organizational learning while integrating individuals, teams, and the organization. Corporate universities have many types: a training department with a new name; a competency/skillbased, career development structure; an initiative driven structure; a leadership development driven structure; a customer/supplier relationship management structure; or a change management structure." (http://www.dptconsulting.com/consulting_cu.htm.) Additionally, DPT assists clients obtain national accreditation certification/credit programs, grant degrees, and develop partnership educational institutions.

Another consulting firm in today's market that tailors corporate education to the companies needs is Corporate Training Solutions (http://www.cts-corporatetraining.com/packet1.html.)

CTS trainers claim that they are experienced practicing and non-practicing employment attorneys who are skilled in employment practices and employment-related litigation. This consulting firm only trains employees in specific work related employment issues. The employment related issue is for the corporation to bring to the employees an already existing program and tailor it to the needs of the corporation. The training includes sexual harassment in the workplace, EEO/Discrimination, Diversity, and conducting workplace investigations. Corporate Training Solutions even makes the claim, which they support by cited case law, that the employer is liable for failure to train, providing inadequate training, instructor misconduct, and training which verifies or acts as evidence of 
wrongdoing such as discrimination. ( 118 S.Ct. 2257, 141 L.2d 633 (1998), 118 S.Ct. 2275, 141 L.Ed 2d 622 (1998), 3 Colo. Code Regs. Sec. 708-1, Rule 80.1 1.)

\section{3. $\quad$ Corporate Educational Programs}

In this scenario corporations work with universities to design specific programs. Corporation needs are met. The university, in its usual role, grants the credits/degrees. Like many on-line programs students learn either on the "campus" of the corporation or over the internet and may never actually visit the host school campus. Moreover, the classes must meet specific criteria and standards set forth by the university.

The role of consultants such as DPT and Corporate Training Solutions provide assistance to the corporations in developing programs or adapting already establishes programs that meet the needs of the corporation itself. These types of consulting firms lead us to segue into the corporate-only based educational programs; in other words, corporate educational programs sponsored by the corporation and maintained by the corporation which follow the corporate mission and are on site of the corporation. Such programs are implemented to varying degrees at Fortune 500 companies such as WalMart, General Electric, General Motors, and Chubb \& Sons, Inc.

\section{Walmart Has Many Corporate Educational Programs}

WalMart has on-the-job training, distance education, computer-based learning, field training, home office training, Pipeline- The Corporate Intranet and First in Line programs (www.walmart.com.)

We all are familiar with on-the-job training so there is no need to discuss this aspect of corporate education. Distance education is used by WalMart television network to broadcast classes each week to locations throughout the U.S. The broadcast allows the home office in Betonville, Arkansas, to explain new operational procedures and showcase new merchandise to hundreds of associates (www.walmart.com.) Further, the computer-based learning provides more than 200 self-paced interactive lessons, which associates receive on computers in every WalMart store. (www.walmart.com.)

Field training is the situation where the regional field trainers facilitate technical and leadership skills to managers with fact-to-face training. (www.walmart.com.) These programs focus on regional and divisional business needs and help develop business relationship skills needed for a successful career. (www.walmart.com.) Field training broadens managerial, technical and leadership skills. Home office training obviously brings the associates to the home office for more than 75 classes that cover a range of learning categories, including technical, managerial and conceptual. The Pipeline provides immediate on-line access of key business information and procedures. (www.walmart.com.) Lastly, the first on line program is designed to initiate students to the corporate structure in their role as interns. http://www.gm.com/company/careers/benefits_edu.

WalMart centers its corporate education primarily on training, not development, based on the goals and corporate mission. If we turn our focus on another type of corporation the focus is different. Let's look at General Motors Corporation.

General Motors Corporation (GM) offers a plethora of corporate educational opportunities such as a Tuition Assistance Program, that regular active salaried employees are eligible for assistance upon date of hire. (http://www.gm.com/company/careers/benefits_edu.) Additionally, graduate education is also available with the operating unit of interest to you for individual opportunities. There are also on-site classwork opportunities. A number of educational courses are offered in conjunction with educational institutions throughout the U.S.

Lastly, General Motors has their own university. This distinguishes GM from most other Fortune 500 corporations. "The General Motors University has established a learning organization for employees across the entire enterprise. The university is designed to focus on the company's training investment with its business needs, and disseminate core values. GMU's main campus is located at the new GM global headquarters in upstate New York, with additional campuses being opened at strategic locations worldwide. GM University on-line will support 
just in time delivery of training information to employees' desktops using the GM intranet." (http://www.gm.com/company/careers/benefits_edu.) GM established the GM University in 1997, organizing it into 16 functional colleges to coordinate its curriculum of 1,300 courses. Each college is managed by a dean, a functional manager who also has a responsibility to create and prioritize that function's training curriculum, under the direction of a Global Function Champion. GM makes training and development a priority in their business mission. This is a stark contrast to the WalMart corporate educational model.

Yet another variation is the General Electric (GE) corporate education philosophy. GE has taken corporate education to a high level and they offer many mentoring programs. In addition, GE has corporate entry-level leadership programs that combine responsible and important job assignments along with formal classroom studies. The rotational assignments cut across different aspects of the GE business. Some of their entry-level leadership educational programs are:

- Communications Leadership Development Program,

- $\quad$ Edison Engineering Development Program,

- $\quad$ Financial Management Program,

- Information Management Leadership Program,

- Operations Management Leadership Program,

- Technical Sales Leadership Program.

Further, GE has business specific educational programs:

- GE Appliances Commercial Leadership Program,

- GE Capital Card Services Management Development Program,

- GE Corporate R7D Software Technology Program,

- GE Financial Assurance Leadership Development Program,

- $\quad$ GE Industrial Systems Field Engineering Program....just to list a few.

The former CEO, Jack Welch, is credited with implementing this extensive educational program. CFO.Com claims that Crotonville, the famed General Electric Company training center in Ossining, New York, is the epicenter of short-term management development seminars for 10,000 of GE's 340,000 worldwide employees each year. (http://www.cfo.com.)

To demonstrate the GE philosophy the company has a two-year Financial Management Program, for delivering on the job and classroom training to 350 college recruits each year. They are the company's prized "FMP's", spending much of their time on six-month "sink or swim" assignments at every GE businesses in 36 countries. They don't graduate or move on to the next level until they have succeeded in a variety of carefully monitored real-world finance assignments, designed to teach them how to be full business partners. " (http://www.cfo.com.)

Additionally, GE has several leadership programs that range from one to two years. An important program is their Global Leadership Development Program ("GLDP"). "This program is not a continuation of business school nor is it a typical training program. GLDP is a practical program designed to build upon existing life and work experiences. It combines real-world work in a global GE Capital business with advanced training in business practices and leadership. Following successful completion, GLDP graduates will have the opportunity to take on a substantial leadership role within their placement country or region." http://www.gecareers.com/GECapital/ intergldp.html.)

\section{Case Example Of A Medium-Sized Corporation}

The corporation that serves as the example for his research is a mid-sized engineering firm in the northeast of the United States. The Engineering Firm (TEF) employs approximately 1100 people. TEF has engaged in an employee development program that includes both training and education and has made employee development one 
of its strategic goals. Their plan is to expand the offerings from the two recurring programs, one in training and one in the area of education, to several in each category. This description shall focus on the education program, the Management of Change (MOC).

The eighty-hour program includes a wide range of topics normally found in an MBA curriculum. Communication, Assertiveness, Conflict Management, Negotiation, Leadership, Working in Teams, Performance Evaluation, Diversity, Listening and Writing Skills, Stress Management and Executive Manners comprise the subject matter. The material is disseminated through the use of lectures and is reinforced by active learning.

The goals of the program are:

- To spread the corporate culture,

- To introduce peers from various locations of the company to one another,

- To cross-fertilize the various lines of business,

- $\quad$ To hone people skills typically absent from technical curricula,

- To increase employees' people skills.

Evaluation of the program, now in its fourth year, indicates that the above-mentioned goals are being met. Over 130 people have taken the course. The company has been acclaimed in the Zweig White Letter as a "Hot firm in 2002" for it 80 hour graduate level leadership course. Within the firm the surveyed employees indicate satisfaction and vie for the opportunity to take the course. There is a waiting list.

Care is taken in selection of participants so that the demographic of the class reflect the demographics of the company. Overall women comprise $22 \%$ of the workforce. This same percentage has completed the program. Of the 110 officers of this privately held company $32.7 \%$ have completed the course.

Current plans include an executive version of the course to include the other corporation officers and an online refresher class for those who have completed the course. While TEF has a tuition reimbursement program for credit awarding institutions and supports employee attendance at technical training seminars it has found that their in-house educational efforts have supported their company goals. They plan to continue to expand their offerings. Our conclusion based on a thorough review of this one company would lead us to believe that a combination of educational offerings is an excellent way to meet employee needs.

\section{Analysis}

Ultimately, one can see the variety in the types of corporate education programs in relation to the types of businesses and the needs of employees. The above review provides background for understanding the training programs of corporations today. The 2002 Training Magazine's Top 100 ranks organizations unsurpassed in harnessing human capital.

One mark of a Top 100 Training Organization is that they have managed, in this uncertain economy, to maintain an unparalleled commitment to workforce development. (http://www.trainingmag.com.) The corporations involved and named in this group have an unwavering commitment to people and their corresponding development in the face of, and sometimes in spite of, the economy. "These Top 100 companies have tacit social contracts with their employees that go well beyond paychecks and perks du jour, solidifying corporate cultures that continually foster and reward both the creation and application of knowledge, not only for the betterment of the company, but for the betterment of the individuals that constitute their workforces as well." (http://www.trainingmag.com.)

Moreover, interestingly, "90\% of the Top 100 companies strategically align personal development plans with overall corporate missions, goals and objectives, while simultaneously providing ample opportunities for individuals to grow and prosper in ways that they desire." (http://www.trainingmag.com.) 
Consistent with the above goals exhibited of the Top corporations is the establishment of governance models within their corporate universities to ensure training's alignment to corporate strategies. General Motors, described earlier, is one such example. The Top 5 of the Top 100 are as follows: 1) Pfizer, 2) Capital One, 3) AmeriCredit, 4) IBM and 5) KLA-Tencor.

In conclusion, the basic idea behind corporate education is not only to increase production but also retention of employees who experience job satisfaction. When companies retain their employees they retain their investment, they retain the productivity without having to re-train employees and they retain creative and experienced employee. Retention leads to a highly successful corporation and is one of the criteria used in the Training survey. The Top 100 companies listed in the Training Magazine are successful because they value their employees by investing in their employees' growth. Organizations that understand the value of going beyond training and into development of their employees will be the excellent companies 2003 and beyond.

Notes 
Notes 